\title{
Effect of Strontium on Structure and Superficial Area of $\mathrm{La}_{2} \mathrm{O}_{3}$
}

\author{
Radia Imane Fertout ${ }^{1 *}$, Madani Ghelamallah ${ }^{2}$, Soufi Kacimi ${ }^{1,3}$ \\ ${ }^{1}$ Laboratoire de Matériaux et Catalyse, Département de Chimie, Faculté des Sciences, \\ Université Djillali Liabes, Sidi Bel Abbès, Algérie \\ ${ }^{2}$ Laboratoire de Matériaux, Applications et Environnement, Département des Sciences de la Matière, \\ Faculté des Sciences et de la Technologie, Université de Mascara, Mascara, Algérie \\ ${ }^{3}$ Centre Universitaire d'Aïn-Témouchent (CUAT), Aïn-Témouchent, Algérie \\ Email: ${ }^{*}$ rfertout@yahoo.fr
}

Received June 27, 2011; revised October 23, 2011; accepted December 19, 2011

\begin{abstract}
Recently, lanthanum oxide doped by group $\mathrm{II}_{\mathrm{A}}$ elements may strongly influence solid state reaction. A series of samples, noted $\mathrm{LaSrX}$ (where $\mathrm{X}=\%$ atomic of strontium) have been prepared by hydrolysis, in neutral medium from $\mathrm{La}_{2} \mathrm{O}_{3}$ and $\mathrm{SrCO}_{3}$. These samples were calcined under air at $450^{\circ} \mathrm{C}$ and $1150^{\circ} \mathrm{C}$ then characterized by specific surface area (BET), $\mathrm{X}$-ray diffraction, scanning electron microscopy (SEM), thermogravimetry (TG) and differential thermal analysis (DTA). Obtained results show that after calcinations at: 1) $450^{\circ} \mathrm{C}$, the addition of strontium is without effect on surface of $\mathrm{La}_{2} \mathrm{O}_{3}$ and the XRD analysis revealed no interaction between lanthanum oxide and strontium carbonate; 2) $1150^{\circ} \mathrm{C}$, the sintering of the samples is very important, reduction of $70 \%$ of surfaces compared to the samples calcined at $450^{\circ} \mathrm{C}$; XRD results show that $\mathrm{LaSrX}$ are formed principally by two oxides: $\mathrm{SrLa}_{2} \mathrm{O}_{4}$ and $\mathrm{La}_{2} \mathrm{O}_{3}$, which is confirmed by SEM method. The reaction between $\mathrm{La}_{2} \mathrm{O}_{3}$ and $\mathrm{SrCO}_{3}$ showed three endothermic weight losses; elimination of water, a partial de-hydroxylation of $\mathrm{La}(\mathrm{OH})_{3}$ and formation of $\mathrm{La}_{2} \mathrm{O}_{2} \mathrm{CO}_{3}$ and $\mathrm{La}_{2}\left(\mathrm{CO}_{3}\right)_{3}$.
\end{abstract}

Keywords: $\mathrm{La}_{2} \mathrm{O}_{3}$; Strontium; Calcination; Surface; Structure; TG-DTA

\section{Introduction}

The literatures [1-5] show that the rare earth oxides (REO) are very interesting in the conversion of greenhouse gases; particularly the valorisation of methane by direct oxidation or dry reforming and the reduction of nitrogen oxides. The ceria and lanthanum oxides are the most used and studied in catalysis. The literatures show that these oxides suffer significant damage under the reactions conditions: lower activities, reduction in surfaces... Recently we showed that the barium stabilizes $\mathrm{La}_{2} \mathrm{O}_{3}$ by its interaction and insertion [6].

We are interested in the effect of the elements of the group $\mathrm{II}_{\mathrm{A}}$ on the REO; in this paper we reported the results of a study on the effect of strontium on $\mathrm{La}_{2} \mathrm{O}_{3}$.

\section{Experimental}

\subsection{Preparation of the Samples}

The samples are obtained according to the method used previously [6,7] in our laboratory. These samples are noted $\operatorname{LaSrX}, \mathrm{X}(=0,5,10,15$ and 20$)$ indicates the atomic percentage of strontium (Table 1). These samples

*Corresponding author. are then calcined under air $(3 \mathrm{~L} / \mathrm{h})$ at $450^{\circ} \mathrm{C}$ and $1150^{\circ} \mathrm{C}$ during 3 hours.

\subsection{Characterizations of the Samples}

\subsubsection{Surfaces Specific Measurements (BET)}

Measurements of surfaces samples are carried out, by adsorption of $\mathrm{N}_{2}$ at $77 \mathrm{~K}$, on 1 gram of powder using Micrometrics ASAP 2000 apparatus.

\subsubsection{Analysis by X-Rays Diffraction (XRD)}

The apparatus used is a standard diffractometer Philips PW 1800 with cylindrical chamber of $36 \mathrm{~mm}$. The tension of this apparatus is of $40 \mathrm{kV}$, the current is around $30 \mathrm{~mA}$. The radiations are the $\mathrm{K}_{\alpha}$ of copper: $\mathrm{K}_{\alpha 1}(1.554056$ $\AA)$ and $\mathrm{K}_{\alpha 2}(1.54439 \AA)$; these can be easy separated because the ratio of their intensities is about 0.500. A nickel filter is used to eliminate the radiation $\mathrm{K}_{\beta}$ from copper. The spectra obtained are indexed according to JCPDS file (Joint Committee one Powder Diffraction Standards).

Table 1. Composition of LaSrX samples.

\begin{tabular}{cccccc}
\hline$\%$ Sr(at) & 0 & 5 & 10 & 15 & 20 \\
\hline $\mathrm{La}_{2} \mathrm{O}_{3}$ & LaSr0 & LaSr5 & LaSr10 & LaSr15 & LaSr20 \\
\hline
\end{tabular}




\subsubsection{Scanning Electron Microscopy (SEM)}

A JEOL JSM-35 scanning electron microscope (SEM) was employed to study the particle morphology. Prior to SEM observations, samples were deposited from ethalonic solution on to holey-carbon copper grids.

\subsubsection{Thermogravimetric Analysis (TG and DTA)}

The thermobalance used is a SETARAM TG-DTA92-16 including an electric balance with continuous signal, a furnace equipped with a regulator-programmer of temperature and a recorder. Measurement is made under oxidizing atmosphere (air: $3 \mathrm{~L} \cdot \mathrm{h}^{-1}$ ) with a speed of heating of $10^{\circ} \mathrm{C} \cdot \mathrm{min}^{-1}$ from ambient to $1200^{\circ} \mathrm{C}$.

\section{Results and Discussion}

\subsection{Effects of Strontium on Surfaces of $\mathrm{La}_{2} \mathrm{O}_{3}$}

The calcinations at $450^{\circ} \mathrm{C}$ showed that the strontium addition is without effect on surfaces of lanthanum oxide (Figure 1). Surfaces of the LaSrX samples are practically the algebraic sums "Equation 1" of surfaces of $\mathrm{La}_{2} \mathrm{O}_{3}$ and $\mathrm{SrCO}_{3}$. This result is in favour of the segregation of lanthanum (III) and strontium carbonate.

$$
\mathrm{S}=(1-\mathrm{X}) \cdot \mathrm{S}_{\mathrm{LaSr} 0}+\mathrm{X} \cdot \mathrm{S}_{\mathrm{SrCO}_{3}}
$$

Nevertheless, one notes a light surface enrichment of strontium for the samples LaSr5 and LaSr10, starting from $X=20$ this tendency is reversed.

At $1150^{\circ} \mathrm{C}$, the addition of 5 and $10 \%$ of strontium make slightly increase the surface of lanthanum oxide. This increase is $3.37 \%$ and $9.16 \%$ respectively for $\mathrm{LaSr} 5$ and $\mathrm{LaSr} 10$. Beyond $15 \%$ no effect on surface of $\mathrm{La}_{2} \mathrm{O}_{3}$ is detected. Reported on Figure 1, the measurements of surfaces show a surface enrichment with lanthanum for the samples $\operatorname{LaSr} 5$ and $\operatorname{LaSr} 15$ and particularly for LaSr10.

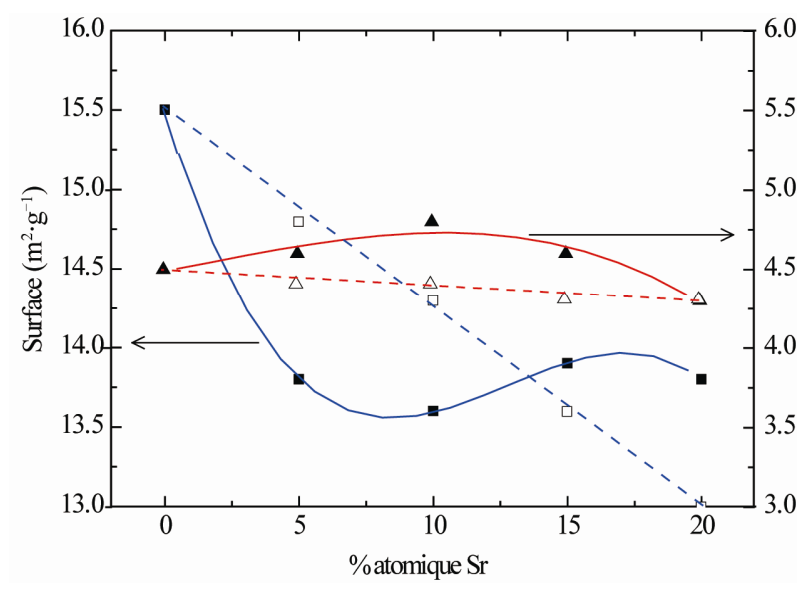

Figure 1. Surfaces of the LaSrX samples calcined under air at $450^{\circ} \mathrm{C}$; $\square$ : measured, $\square$ : calculated) and at $1150^{\circ} \mathrm{C}(\boldsymbol{\Delta}$ : measured, $\triangle$ : calculated).

\subsection{Characterization of the Samples by XRD and Microscopy SEM}

\subsubsection{Samples Calcined at $450^{\circ} \mathrm{C}$}

The XRD patterns of LaSrX calcined at $450^{\circ} \mathrm{C}$ are reported on Figure 2. The analysis of these spectra shows that the samples are mixtures of composed containing lanthanum (carbonates, oxides, oxy-hydroxides, hydroxides and oxy-carbonates) and of strontium carbonate. $\mathrm{La}(\mathrm{OH})_{3}$ is in a majority [6] and crystallizes according to a hexagonal system pertaining to the space group $\mathrm{P}_{3 / \mathrm{mmc}}$ with parameters $\mathrm{a}=4.06 \AA$ and $\mathrm{c}=6.43 \AA$, in accordance with JCPDS files. These results showed no interaction between lanthanum oxide and strontium carbonate. Sure enough the comparison between the spectra of the LaSrX samples and that of $\mathrm{LaSr} 0$ indicates a whole of lines at $2 \theta=25^{\circ}, 26^{\circ}, 37^{\circ}$ and $44^{\circ}$ (Figure 2) specific to $\mathrm{SrCO}_{3}$. The intensity of these lines increases with $\mathrm{X}$, the addition of strontium. These results are in agreement with those of the literature [8]. After calcinations at $450^{\circ} \mathrm{C}$, one observes partial or total de-hydroxylation of the hydroxide of lanthanum $\mathrm{La}(\mathrm{OH})_{3}$ and probably according to following reactions:

$$
\begin{aligned}
& \mathrm{La}(\mathrm{OH})_{3} \rightarrow \mathrm{LaO}(\mathrm{OH})+\mathrm{H}_{2} \mathrm{O} \\
& 2 \mathrm{LaO}(\mathrm{OH}) \rightarrow \mathrm{La}_{2} \mathrm{O}_{3}+\mathrm{H}_{2} \mathrm{O} \\
& 4 \mathrm{LaO}(\mathrm{OH})+\left[\mathrm{CO}_{2}, \mathrm{CO}_{3}^{2-}\right] \\
& \rightarrow \mathrm{La}_{2} \mathrm{O}_{2} \mathrm{CO}_{3}+\mathrm{La}_{2}\left(\mathrm{CO}_{3}\right)_{3}+2 \mathrm{H}_{2} \mathrm{O}
\end{aligned}
$$

The formation of lanthanum oxy-carbonates is very frequent when $\mathrm{La}_{2} \mathrm{O}_{3}$ is used in catalysis [9-11]. Indeed

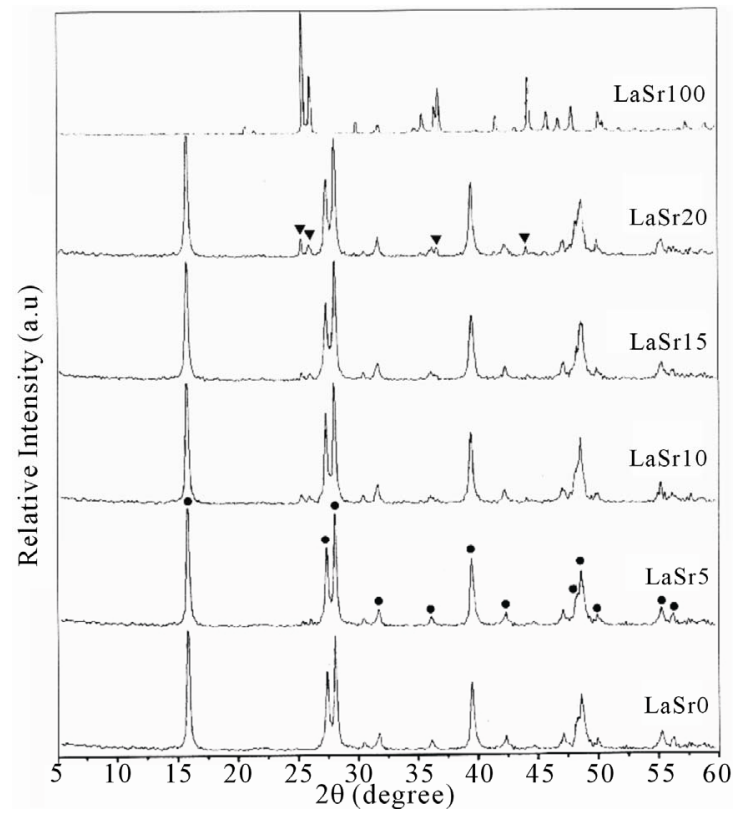

Figure 2. XRD patterns of LaSrX samples calcined under air at $450^{\circ} \mathrm{C}$; Mixture of $\mathrm{La}(\mathrm{OH})_{3}$ and/or $\mathrm{La}_{2} \mathrm{O}_{2} \mathrm{CO}_{3}(\bullet)$, and $\mathrm{SrCO}_{3}(\nabla)$. 
$\mathrm{La}_{2} \mathrm{O}_{3}$ activates $\mathrm{CO}_{2}$ in the form of $\mathrm{La}_{2} \mathrm{O}_{2} \mathrm{CO}_{3}$, during the reactions using $\mathrm{CO}_{2}[12,13]$. XRD patterns of the samples show clearly the crystalline phase of $\mathrm{La}_{2} \mathrm{O}_{2} \mathrm{CO}_{3}$ (Figure 2) this one is promoted by the presence of strontium.

\subsubsection{Samples Calcined at $1150^{\circ} \mathrm{C}$}

The analysis of XRD patterns reported in Figure 3, shows that samples are formed principally by two oxides: a mixed compounds with structure of $\mathrm{SrLa}_{2} \mathrm{O}_{4}$ and $\mathrm{La}_{2} \mathrm{O}_{3}$ [6]; the $\mathrm{La}_{4} \mathrm{Sr}_{3} \mathrm{O}_{9}, \mathrm{La}_{4} \mathrm{SrO}_{7}$ and $\mathrm{La}_{2} \mathrm{Sr}_{2} \mathrm{O}_{5}$ appears after treatment at $1500^{\circ} \mathrm{C}$ [14].

The interaction and the insertion of strontium in $\mathrm{La}_{2} \mathrm{O}_{3}$ are confirmed by the absence of the position of $\mathrm{SrO}$ on the spectra of the LaSrX samples. The literature [2] shows that the strontium oxide is not detected by XRD after calcinations between $800^{\circ} \mathrm{C}$ and $950^{\circ} \mathrm{C}$. This result are confirmed by scanning electron microscopy, the SEM of sample LaSr 15 calcined at $1150^{\circ} \mathrm{C}$ (Figure 4), shows porous phase with two homogenous regions probably for $\mathrm{SrLa}_{2} \mathrm{O}_{4}$ and $\mathrm{La}_{2} \mathrm{O}_{3}$.

\subsection{Thermogravimetric Analysis}

Thermogravimetric measurements (TG and DTA), of samples from ambient to $1000^{\circ} \mathrm{C}$, are reported on Figures 5(a)-(f).

\subsubsection{TG and DTA of the Precursors Alone}

The TG curve, represented on the Figure 5(a), indicates three losses of mass for LaSr100. The first change of

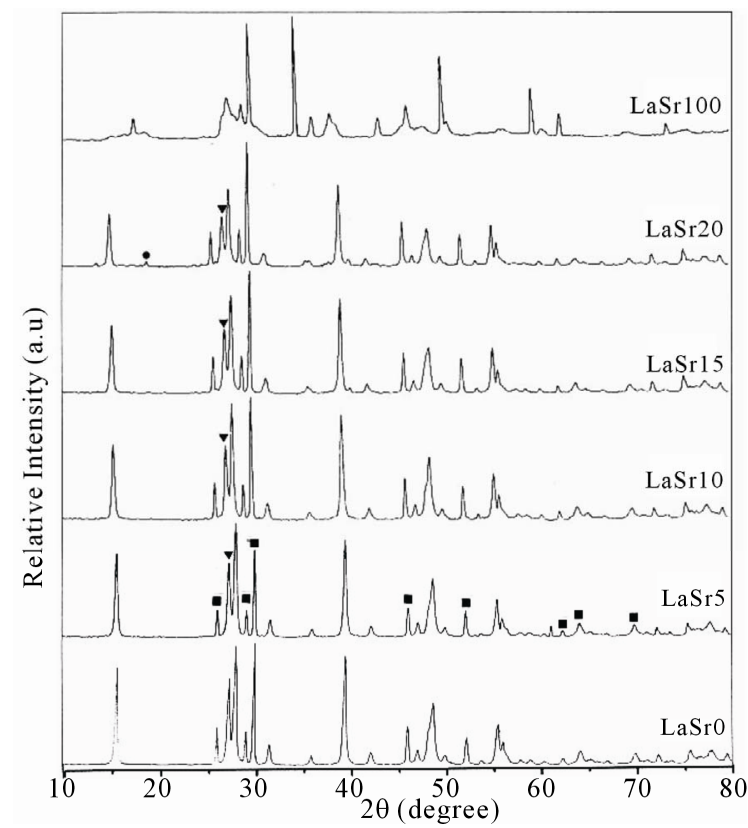

Figure 3. XRD patterns of LaSrX samples calcined under air at $1150^{\circ} \mathrm{C}$. Mixtures of $\mathrm{SrLa}_{2} \mathrm{O}_{4}($ raies $\square), \mathrm{La}_{2} \mathrm{O}_{3}(\nabla)$ and metallic strontium $(\bullet)$.

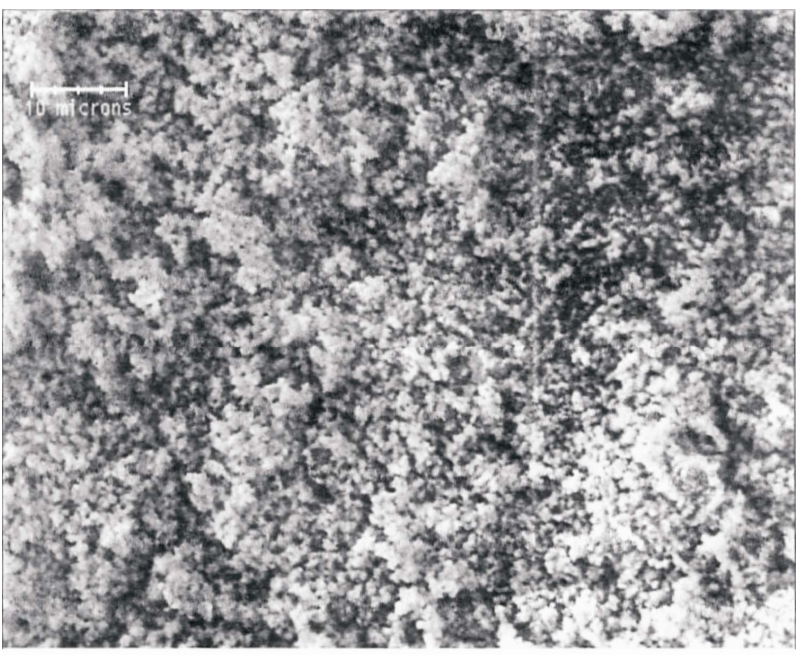

$\mathrm{La} 15 \mathrm{Sr} \times 150015 \mathrm{KV}$

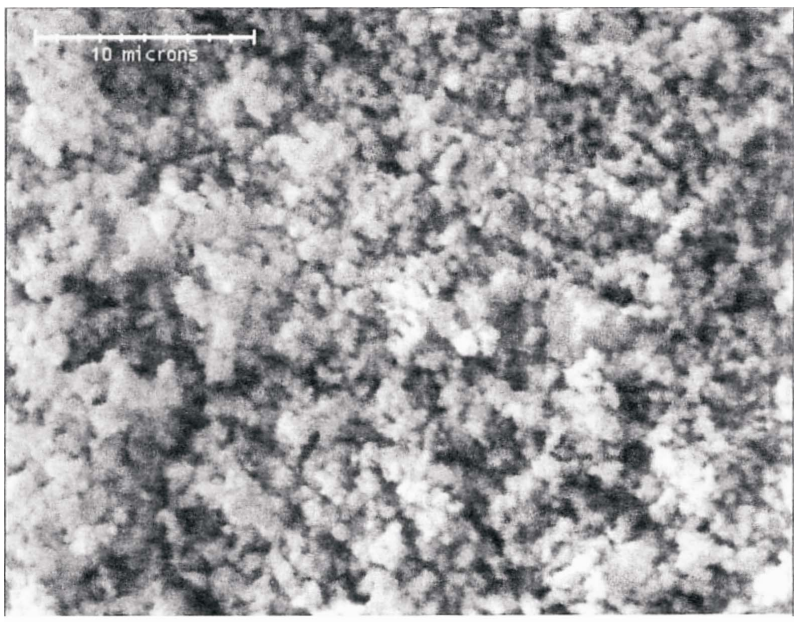

$\mathrm{La} 15 \mathrm{Sr} \times 350015 \mathrm{KV}$

Figure 4. Micrography SEM for sample LaSr15 calcined at $1150^{\circ} \mathrm{C}$, Above: LaSr15 ×1500 KV, Below: LaSr15 ×3500 KV.

mass of about $0.53 \%$, which intervenes with $100^{\circ} \mathrm{C}$, corresponds at the beginning of the water of hydratation. One second loss of mass of $15 \%$ starts as of $480^{\circ} \mathrm{C}$ to finish with $620^{\circ} \mathrm{C}$ approximately. In this temperature range, it has formation of $\mathrm{SrO}_{2}$ according to the "Reaction (5)"; the decomposition of $\mathrm{SrCO}_{3}$ in $\mathrm{SrO}$ and $\mathrm{CO}_{2}$ usually proceeds towards $1300^{\circ} \mathrm{C}[13]$

$$
\mathrm{SrCO}_{3} \rightarrow \mathrm{SrO}_{2}+\mathrm{CO}
$$

DTA curves show, in this range of temperature, three peaks of endothermic reactions. The first two fine peaks, towards $480^{\circ} \mathrm{C}-540^{\circ} \mathrm{C}$, correspond to the phase shift of $\mathrm{SrCO}_{3}$ [15]; the third towards $600^{\circ} \mathrm{C}$ is due to the reaction (5). Indeed, the TG shows that the ratio

$\frac{\Delta m_{\text {mesured }}}{\Delta m_{\text {calculated }}}=0.8$ is close to the stoichiometry of CO. The third change which takes place towards $900^{\circ} \mathrm{C}$ shows a loss of mass of $0.62 \%$ which could be allotted to a sub- 


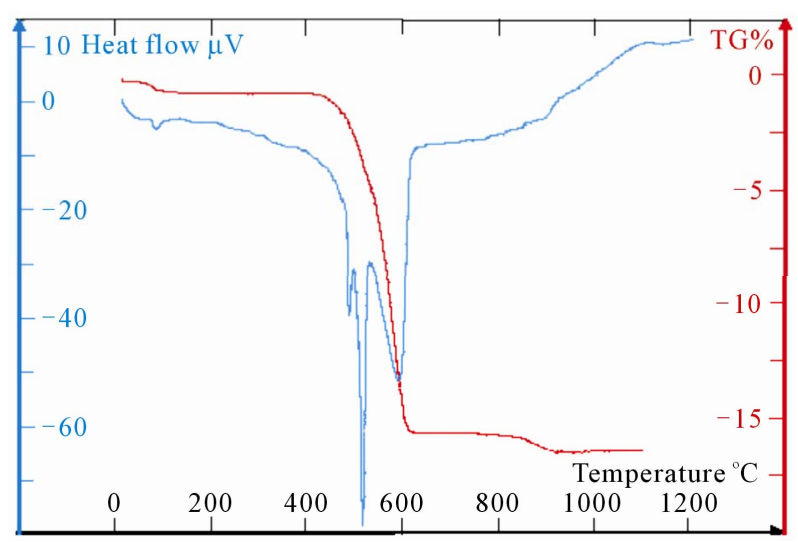

(a)

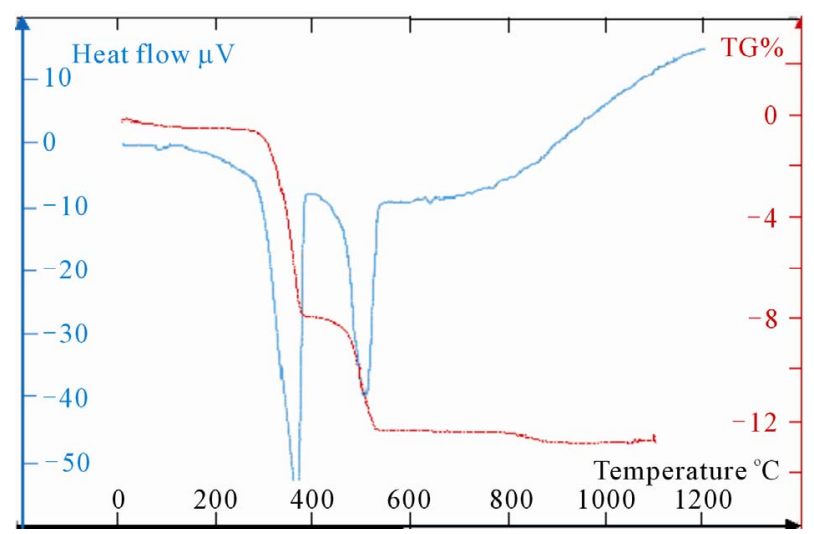

(c)

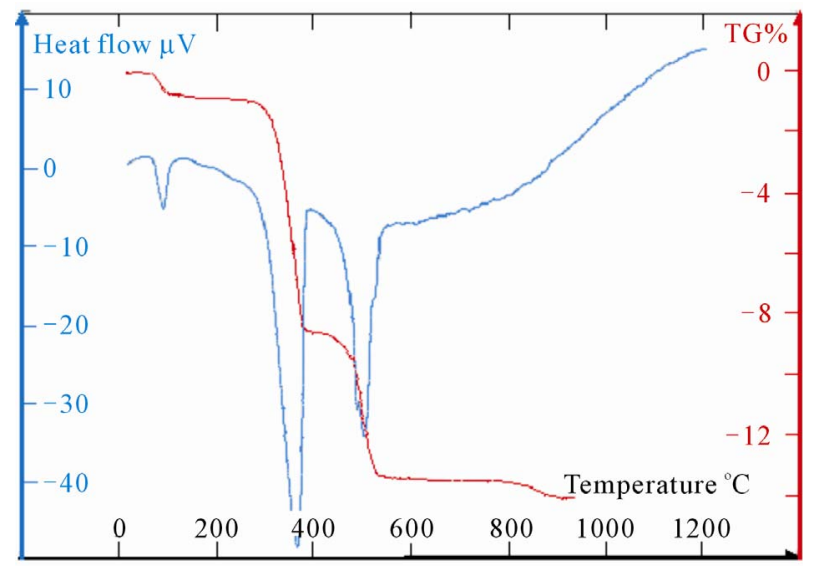

(e)

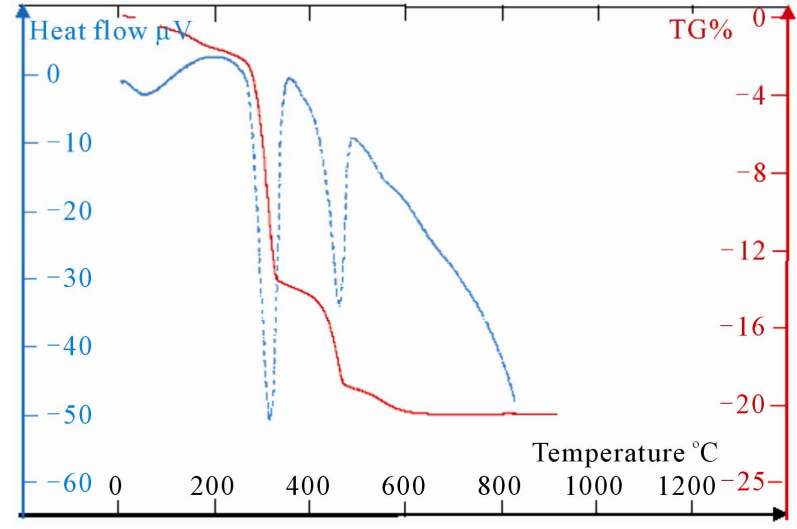

(b)

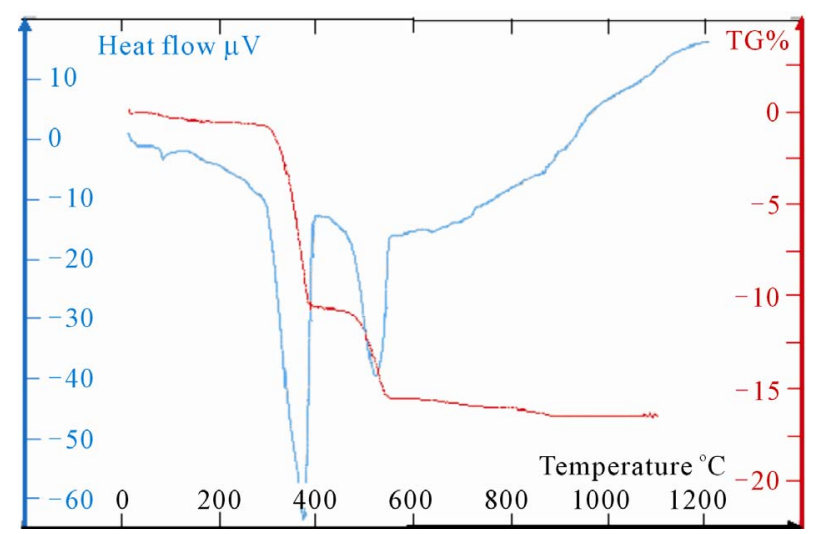

(d)

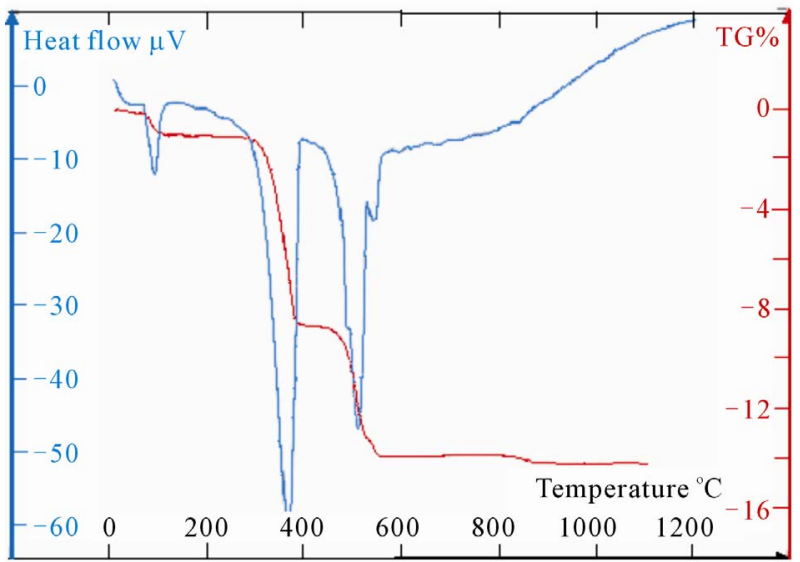

(f)

Figure 5. (a): TG and DTA of LaSr100; (b):TG and DTA of LaSr0; (c): TG and DTA of LaSr5; (d): TG and DTA of LaSr10; (e): TG and DTA of LaSr15; (f): TG and DTA of LaSr20.

limation of metal strontium coming from the decomposition of $1 \%$ of $\mathrm{SrO}_{2}$ "Reaction (6)".

$$
\mathrm{SrO}_{2} \rightarrow \mathrm{Sr}+\mathrm{O}_{2}
$$

For LaSr0, the Figure 5(b) shows four losses of mass corresponding to four reactions.

The first, below $300^{\circ} \mathrm{C}$ indicates the drainage of water.
The formation of $\mathrm{La}_{2} \mathrm{O}_{3}$ is obtained after two stages "Reactions (7) and (8)" of the de-hydroxylation of $\mathrm{La}(\mathrm{OH})_{3}$. Between $350^{\circ} \mathrm{C}$ and $400^{\circ} \mathrm{C}$ a loss of mass, about $7.76 \%$, is attributed to the appearance of lanthanum oxy-hydroxides, and that of $\mathrm{La}_{2} \mathrm{O}_{3}$ worms $500^{\circ} \mathrm{C}$. Finally between $650^{\circ} \mathrm{C}$ and $800^{\circ} \mathrm{C}$, a loss of mass of $3.18 \%$ could be due to the de-carboxylation of $\mathrm{La}_{2} \mathrm{O}_{2} \mathrm{CO}_{3}$, 
according to the "Reaction (9)". This compound comes from the easy carbonation of lanthanum oxide and of the tri-hydroxide $\mathrm{La}(\mathrm{OH})_{3}$ with the free air [8].

$$
\begin{gathered}
\mathrm{La}(\mathrm{OH})_{3} \rightarrow \mathrm{LaO}(\mathrm{OH})+\mathrm{H}_{2} \mathrm{O} \\
2 \mathrm{LaO}(\mathrm{OH}) \rightarrow \mathrm{La}_{2} \mathrm{O}_{3}+\mathrm{H}_{2} \mathrm{O} \\
\mathrm{La}_{2} \mathrm{O}_{2} \mathrm{CO}_{3} \rightarrow \mathrm{La}_{2} \mathrm{O}_{3}+\mathrm{CO}_{2}
\end{gathered}
$$

\subsubsection{TG and DTA of LaSrX Samples}

Measurements TG and DTA of the samples $\operatorname{LaSrX}(\mathrm{X}=$ 5, 10, 15 and 20) are reported on the Figures 5(c)-(f). The TG shows four stages of losses of mass. First is due to the removal of water towards $100^{\circ} \mathrm{C}$. The last one towards $900^{\circ} \mathrm{C}$ is very weak and does not exceed the $0.25 \%$ for the four samples. As for the two other significant changes of mass one notes two different behaviours. Indeed, the DTA shows two simple peaks worms $380^{\circ} \mathrm{C}$ and the other towards $560^{\circ} \mathrm{C}$ for the samples LaSr5 and LaSr10; on the other hand for LaSr15 and LaSr20 the second peak presents two distinct shoulders. For the first couple of samples it had two reactions and four reactions for the second couple of samples.

\section{- Samples LaSr5 and LaSr10}

Towards $560^{\circ} \mathrm{C}$, the change of mass is neither representative of $\mathrm{La}(\mathrm{OH})_{3}$ (Figure 5(b)) or that of $\mathrm{SrCO}_{3}$ (Figure 5(a)).

$\mathrm{LaO}(\mathrm{OH})$ exit of the de-hydroxylation of $\mathrm{La}(\mathrm{OH})_{3}$ reacts with $\mathrm{SrCO}_{3}$ to form a mixed oxide according to "Reaction (10)".

$$
2 \mathrm{LaO}(\mathrm{OH})+\mathrm{SrCO}_{3} \rightarrow \mathrm{SrLa}_{2} \mathrm{O}_{4}+\mathrm{CO}_{2}+\mathrm{H}_{2} \mathrm{O}
$$

\section{- Samples LaSr15 and LaSr20}

Three peaks DTA, represented on the Figures 5(e) and (f), which makes the superposition of three pics, it can be to explain by the two phases shifts of strontium carbonate and by the departure of $\mathrm{CO}$ coming from the decomposition of $\mathrm{SrCO}_{3}$ according to the "Reaction (5)". Nevertheless, the formation of the mixed compound $\mathrm{SrLa}_{2} \mathrm{O}_{4} \mathrm{Re}$ action (10) is not excluded. This reaction would be supported by an acid catalysis of the ions $\mathrm{La}^{3+}$. The quantity of this mixed oxide would be weak and equivalent to that obtained during the treatment of LaSr5 and LaSr10.

Lastly, it should be noted that contrary to the samples LaSr5 and LaSr10, quantity of water which is eliminated from the samples $\mathrm{LaSr} 15$ and $\mathrm{LaSr} 20$ towards $100^{\circ} \mathrm{C}$ is relatively more significant. This water accounts for $1.5 \%$ $(\Delta m / m)$ of the treated mass.

\section{Conclusions}

A series of samples, LaSrX where $\mathrm{X}$ is the atomic percentage in strontium was prepared by hydrolysis of $\mathrm{La}_{2} \mathrm{O}_{3}$ and $\mathrm{SrCO}_{3}$ in neutral medium. These samples was calcined under air at $450^{\circ} \mathrm{C}$ and $1150^{\circ} \mathrm{C}$, then characterized by BET specific surface area, XRD analysis and
SEM microscopy. The reactivity of lanthanum oxide and $\mathrm{SrCO}_{3}$ was followed by TG and DTA.

After calcination at $450^{\circ} \mathrm{C}$, the addition of strontium is without effect on surfaces of lanthanum oxide. The XRD patterns shows data for crystalline phases of $\mathrm{La}_{2} \mathrm{O}_{3}$, $\mathrm{La}(\mathrm{OH})_{3}, \mathrm{LaO}(\mathrm{OH})$ and $\mathrm{La}_{2} \mathrm{O}_{2} \mathrm{CO}_{3}$ and of strontium carbonate. There are no interaction between lanthanum oxide and strontium carbonate.

After calcinations at $1150^{\circ} \mathrm{C}$, the addition of $5 \%$ and $10 \%$ of strontium make slightly increase the specific surface of lanthanum oxide, at this temperature the sintering is important, $70 \%$ of values of the surfaces are decreases compared to those calcined at $450^{\circ} \mathrm{C}$. The XRD spectra shows that $\mathrm{LaSrX}$ samples are formed by two oxides: a mixed compounds with structure of $\mathrm{SrLa}_{2} \mathrm{O}_{4}$ and $\mathrm{La}_{2} \mathrm{O}_{3}$. This result are confirmed by SEM micrography.

The TG curves of pure $\mathrm{La}_{2} \mathrm{O}_{3}$ and $\mathrm{SrCO}_{3}$ indicate that, $\mathrm{SrCO}_{3}$ decompose at $620^{\circ} \mathrm{C}$ approximately and the weight losses of $\mathrm{La}_{2} \mathrm{O}_{3}$ result for the drainage of water and the partial de-hydroxylation of $\mathrm{La}(\mathrm{OH})_{3}$ with formation of $\mathrm{LaO}(\mathrm{OH})$. The reactivity of $\mathrm{LaSrX}$ showed three endothermic weight losses; elimination of water, a partial de-hydroxylation of $\mathrm{La}(\mathrm{OH})_{3}$ and formation of $\mathrm{La}_{2} \mathrm{O}_{2} \mathrm{CO}_{3}$ and $\mathrm{La}_{2}\left(\mathrm{CO}_{3}\right)_{3}$. In the range of temperature of $500^{\circ} \mathrm{C}-$ $580^{\circ} \mathrm{C}$ the DTA indicates, a first allotropic transition from the $\mathrm{SrO}_{2}$ and its decomposition on $\mathrm{CO}$ and $\mathrm{SrO}_{2}$ for LaSr 15 and LaSr20.

\section{REFERENCES}

[1] M. C. J. Bradford and M. A. Vannice, " $\mathrm{CO}_{2}$ Reforming of $\mathrm{CH}_{4}$," Catalysis Reviews: Science and Engineering, Vol. 41, No. 1, 1999, pp. 1-42. doi:10.1081/CR-100101948

[2] T. Le Van, C. Louis, M. Kermarec, M. Che and J. M. Tatibouët, "Temperature and Conversion Dependence of Selectivities in Oxidative Coupling of Methane on $\mathrm{La}_{2} \mathrm{O}_{3}$ Catalysts," Catalysis Today, Vol. 13, No. 2-3, 1992, pp. 321-328. doi:10.1016/0920-5861(92)80156-H

[3] A. Trovarelli, C. De Leitenburg and G. Dolcetti, "Design Better Cerium-Based Oxidation Catalysts," Chemtech, Vol. 27, No. 6, 1997, pp. 32-37.

[4] S. J. Huang, A. B. Walters and M. A. Vannice, "NO Reduction with $\mathrm{H}_{2}$ or $\mathrm{CO}$ over $\mathrm{La}_{2} \mathrm{O}_{3}$ and Sr-Promoted $\mathrm{La}_{2} \mathrm{O}_{3}$," Journal of Catalysis, Vol. 173, No. 1, 1998, pp. 229-237. doi:10.1006/jcat.1997.1911

[5] M. Traykova, N. Davidova, J.-S. Tsaih and A. H. Weiss, "Oxidative Coupling of Methane-The Transition from Reaction to Transport Control over $\mathrm{La}_{2} \mathrm{O}_{3} / \mathrm{MgO}$ Catalyst," Applied Catalysis A: General, Vol. 169, No. 2, 1998, pp. 237-247.

[6] M. Ghelamallah, S. Kacimi and R. I. Fertout, "Incorporation of Barium in Titanium Oxide and Lanthanum Oxide," Materials Letters, Vol. 59, No. 6, 2005, pp. 714-718. doi:10.1016/j.matlet.2004.06.072

[7] M. D. Mitchell and M. A. Vannice, "Adsorption and Ca- 
talytic Behavior of Palladium Dispersed on Rare Earth Oxides," Industrial and Engineering Chemistry Fundamentals, Vol. 23, No. 1, 1984, pp. 88-96. doi:10.1021/i100013a016

[8] A. Galenda, M. M. Natile, L. Nodari and A. Glisenti, " $\mathrm{La}_{0.8} \mathrm{Sr}_{0.2} \mathrm{Ga}_{0.8} \mathrm{Fe}_{0.2} \mathrm{O}_{3-\delta}$ : Influence of the Preparation Procedure on Reactivity toward Methanol and Ethanol," Applied Catalysis B: Environmental, Vol. 97, No. 3-4, 2010, pp. 307-322. doi:10.1016/j.apcatb.2010.04.004

[9] T. J. Toops, A. B. Walters and M. A. Vannice, "The Effect of $\mathrm{CO}_{2}$ and $\mathrm{H}_{2} \mathrm{O}$ on the Kinetics of NO Reduction by $\mathrm{CH}_{4}$ over a $\mathrm{La}_{2} \mathrm{O}_{3} / \gamma-\mathrm{Al}_{2} \mathrm{O}_{3}$ Catalyst," Journal of Catalysis, Vol. 214, No. 2, 2003, pp. 292-307. doi:10.1016/S0021-9517(02)00092-1

[10] L. M. Cornaglia, J. Munera, S. Irusta and E. A. Lombardo, "Raman Studies of $\mathrm{Rh}$ and $\mathrm{Pt}$ on $\mathrm{La}_{2} \mathrm{O}_{3}$ Catalysts Used in a Membrane Reactor for Hydrogen Production," Applied Catalysis A: General, Vol. 263, No. 1, 2004, pp. 91-101. doi:10.1016/j.apcata.2003.12.003
[11] K. Matsuzawa, T. Mizusaki, S. Mitsushima, N. Kamiya and K. Ota, "The Effect of La Oxide Additive on the Solubility of $\mathrm{NiO}$ in Molten Carbonates," Journal of Power Sources, Vol. 140, No. 2, 2005, pp. 258-263. doi:10.1016/j.jpowsour.2004.08.041

[12] T. J. Toops, A. B. Walters and M. A. Vannice "The Effect of $\mathrm{CO}_{2}$ and $\mathrm{H}_{2} \mathrm{O}$ on the Kinetics of $\mathrm{NO}$ Reduction by $\mathrm{CH}_{4}$ over Sr-Promoted $\mathrm{La}_{2} \mathrm{O}_{3}$," Catalysis Letters, Vol. 82, No. 1-2, 2002, pp.45-57. doi:10.1023/A:1020583806660

[13] B. A. A. Balboul, "The Solid State Reaction between Lanthanum Oxide and Strontium Carbonate," Thermochimica Acta, Vol. 445, No. 1, 2006, pp. 78-81. doi:10.1016/j.tca.2006.03.005

[14] ICDD Diffraction Databases, 1994-1998. International Center for Diffraction Data (CDRom), Newtown Square.

[15] R. C Weast, "Handbook of Chemistry and Physics," 66th Edition, CRC, Boca Raton, 1985-1986, p. B-148. 